P59 (continued)

Pathways Area Health Education Center Scholars (CUP AHEC Scholars) to SNAP-Ed evidence-based curricula. The two-year program combines didactic and experiential activities for students interested in working in underserved communities. Scholars gain competencies in interprofessional education and practice, social determinants of health, and culturally sensitive clinical care. The collaboration promotes an understanding of how nutritionrelated supports create healthier, food-secure communities. Scholars complete an online module covering SNAPEd program theory and participate in community-based activities alongside a nutrition educator.

Evaluation Methods: Post-activity surveys from scholars collect immediate qualitative information on trainings, focused on quality improvements and learning outcomes. Annual post-surveys collect quantitative and qualitative data measuring competency outcomes. A storytelling approach with photographic evidence will highlight results from the collaboration's first 2 years.

Results: Since 2018, 9 students have participated in the Maine SNAP-Ed learning partnership. The majority of students (89\%) report they would recommend the activity to fellow students. Qualitative feedback was overwhelmingly positive, and the most commonly cited learning outcome was increased understanding of "the link between poor nutrition and its impacts on health and wellness."

Conclusions: The health professions training collaboration demonstrates that exposure to SNAP-Ed's approach to addressing social determinants of health provides valuable real-world clinical-community linkages experience. Scholarly partnerships with SNAP-Ed have the potential to create fundamental, systemic change in local capacity to reduce the burden of hunger and improve health outcomes.

Funding: Supplemental Nutrition Assistance Program Education.

\section{P60 The Effectiveness of Nutrition Education: Comparing Registered Dietitian Educators and Dietetic Interns}

Amy Gannon,EdD,LD, RDN, amy.gannon@marshall.edu, Marshall University, Department of Dietetics, One John Marshall Dr, Huntington, WV, 25755

Background: The Marshall University Nutrition Education Program (MUNEP) delivers nutrition education to needy elementary schools (grades K-2) in rural West Virginia. This dissertation research reviewed pre-/post-tests and teacher focus group findings comparing effectiveness of RDN educators and dietetic intern (DI) educators in program delivery. DI educators have no formal educational training or pedagogical practice compared to RDNs, yet they play a significant role in program implementation.

Objective: To examine differences in knowledge/behavior change based on pre-/post-scores after an intervention of nutrition education lessons by RDN educators/DI educators; and to compare the effectiveness of RDN educators/DI educators through teacher focus group findings.
Study Design, Setting, Participants: A mixed-methods, retrospective study of (15) knowledge/behavior-change questions on student pre-/post-tests $(n=1160)$ comparing RDN/DI educators; and results of teacher focus groups $(n=4)$, with teachers $(n=30)$ examining the effectiveness of RDN/DI educators in program implementation.

Measurable Outcome/Analysis: Quantitative analysis included independent t-tests comparing pre-/post-test scores for overall knowledge/behavior change; independent t-tests examining post-test scores for overall behavior/overall knowledge and comparing RDN/DI educators; post-hoc Bonferroni ANOVA analysis comparing post-test scores to free/reduced-priced (FR) meals in needy schools. Qualitative inquiry included thematic analysis to compare effectiveness of RDN/DI educators.

Results: Overall knowledge change from pre- to post-test was statistically significant $(P=.000)$; no significant difference in overall behavior change from pre- to post-test $(P=.710)$, or comparison between RDN/DI educators $(P=.175$ for knowledge change; $P=.479$ for behavior change) were found. Statistical significance existed for post hoc review of students' post-tests and socio-economic status based on percentage of FR school meals for students in the 50\%-59\% FR meal category vs students in the 90\%$100 \%$ FR meal category $(P=.017)$. Focus groups showed that RDN educators were empowered in the classroom and had better management than DI educators; taste-testing is a critical component for both RDN/DI educators.

Conclusions: This study adds to limited data comparing effectiveness of RDN/DI educators in nutrition education. Results will be used to inform DI training, improve MUNEP participant experience related to knowledge and behavior change, and to improve MUNEP experience in needy schools.

Funding: Supplemental Nutrition Assistance Program Education.

\section{P61 SNAP-Ed Participants Improved and Maintained Healthy Eating and Shopping Behaviors Following the 4-Week 10 Tips Intervention}

Patricia Dushuttle,MA, Patricia.Dushuttle@maine.gov, State of Maine-DHHS Office for Family Independence, 109 Capitol Street, SHS \#11, Augusta, ME, 04333; Margaret Wilkin, MPH, Altarum; Rebecca Hofer, MPH, Altarum; Brenda Wolford, MS, RD, Altarum; Brent Walker, MS, RD, Altarum

Objective: To assess the impact of 10 Tips for Adults on healthy eating and shopping behaviors.

Use of Theory or Research: The Social Cognitive Theory states behavior change is predicted by knowledge of health risks and benefits and perceived self-efficacy. 10 Tips aims to increase the likelihood participants will make healthy choices on a budget.

Target Audience: Adults in Maine eligible for Supplemental Nutrition Assistance Program Education (SNAPEd).

Continued on page 545 